\title{
A scoping study investigating student perceptions towards inquiry based learning in the laboratory
}

\author{
Nicola King ${ }^{1}$, Thomas Van der Touw ${ }^{2}$, Lucy Spowart ${ }^{3}$ and Craig Lawlor ${ }^{2}$ \\ ${ }^{1}$ School of Biomedical and Healthcare Sciences, Plymouth University, Plymouth. UK. \\ ${ }^{2}$ School of Science and Technology, University of New England, Armidale. NSW 2351. Australia. \\ ${ }^{3}$ PedRIO and Educational Development, Plymouth University, Plymouth.PL4 8AA. UK. \\ For correspondence: Nicola.king@plymouth.ac.uk
}

\begin{abstract}
There has been an increasing movement towards the introduction of inquiry based learning in undergraduate physiology laboratories. Students can however find this challenging when there is a sudden transition from traditional didacticpracticals to full inquiry based activities. One reason for this could be the students' perceptions about the introduction of inquiry based learning. The aim of this preliminary scoping investigation was to judge students' attitudes towards inquiry based learning following a practical containing an element of inquiry. Students were supplied with approximately $2.5 \mathrm{~cm}$ gastrointestinal ileal loops from guinea-pigs which they connected via a force transducer to recording equipment. Students were also provided with 4 agonists and 4 antagonists for which they had to determine which antagonist paired with which agonist and which order to add the drugs. After the practical students completed a questionnaire and survey. Twenty nine percent of students strongly agreed and $54 \%$ agreed that detailed instructions should be given about how to carry out each practical. In answer to the statement I'd value the opportunity to design and carry out my own experiments, $12 \%$ strongly agreed, whilst $27 \%$ agreed and $48 \%$ were neutral. The commonest anxieties expressed by the students were that they would not understand the practical and not getting the right results. These findings suggest that considerable thought needs to be given as to how to best introduce physiology students to inquiry based practicals and that these student cohorts may benefit from some morescoping activities. Some ideas for these scoping activities are presented.
\end{abstract}

Keywords: inquiry based learning, physiology, gastrointestinal tract.

\section{Introduction}

Traditionally laboratory practicals in undergraduate physiology have involved the students following step-by-step instructions to reproduce the results of well-known experimental phenomena. Not only is this approach regarded as boring by the students (Henige, 2011), but it is reported to limit the development of experimental competencies and conceptual knowledge (Nybo and May, 2015). As a consequence, the focus of the students becomes obtaining the correct results for the laboratory writeup and a failure to understand the whole conception of the experiment (Kolkhorst et al., 2001). On the other hand inquiry based practicals give students the opportunity to create their own hypotheses and design their own experiments. This promotes the development of higher order thinking skills (Kolkhorst et al., 2001, Nybo and May, 2015) such as creativity, critical thinking, independent thinking and reflection (Berg et al., 2003;Casotti et al., 2008; Chaplin, 2003;Myers and Burgess, 2003;Rivers, 2002). It also improves attainment of the desired learning outcomes (DiPasqualeet al., 2003, Furtaket al., 2012, Myers and Burgess, 2003, Nybo and May, 2015). The students become active learners who show greater engagement (Chaplin, 2003)and motivation (Henige, 2011;Rivers, 2002) alongside increased curiosity (Rivers, 2002) and enjoyment (Henige, 2011;Rivers, 2002). 
In view of these advantages why, with the possible exception of exercise physiology (Henige, 2011; Kolkhorst et al., 2001;Nybo and May, 2015), has there been a slow take up of inquiry based learning in physiology practicals? One reason for this could be greater labour intensity as inquiry based practicals are more challenging to write, maintain and coordinate (Casottiet al., 2008). Another possibility could be that the students are not ready for a challenge (Berg et al., 2003) and lack the expertise with the scientific equipment (Casottiet al., 2008;Kolkhorst et al., 2001) and investigative skills (Chaplin, 2003). When inquiry based laboratories have been used consistently students often devise experiments at the same level of sophistication as in their introductory courses (Chaplin, 2003). On the other hand if inquiry based practicals are introduced without any preparation this can increase the students' anxiety and leave them in an uncomfortable struggle with increased frustration (Henige, 2011). It has also been reported that changing a traditional style laboratory course to an inquiry based one does not automatically improve the learning outcomes (Furtaket al., 2012).

The preceding suggests that the question of whether to introduce inquiry based learning physiology practical classes is not straight forward, and that students' attitudes play an important role in determining whether inquiry based physiology practicals can be successfully implemented. Given the dearth of studies dealing with inquiry based practicals in the literature, this suggests that a preliminary scoping study investigating student perceptions about inquiry based learning may be justified. We therefore conducted a questionnaire and survey based study into students' attitudes about inquiry based physiology practicals by administering the questionnaire and survey in the context of a newly designed low level inquiry based practical in gastrointestinal physiology.

\section{Methods}

\section{Ethics approval}

This project was approved by the University of New England (UNE) human research ethics committee and conforms to the Declaration of Helsinki regarding experimentation on humans. The use of guinea-pigs during this study was approved by the UNE animal ethics committee and conforms to the guidelines from Directive 2010/63/EU of the European Parliament on the protection of animals used for scientific purposes.

\section{Study context}

This study was conducted during a second year second trimester physiology course at the University of New England in New South Wales, where students had been introduced for the first time to gastrointestinal physiology. This course was taken by a mixed cohort of students studying for a Bachelor's degree in Animal Sciences, Biomedical Sciences, Exercise and Sports Science, Pharmacy, Science, or Zoology. 81 students out of a total of 113 took part in the study.At the time of the study, the second year students had already gained considerable experience with traditional didactic practical classes, but had not previously been exposed to inquiry based practicals. Therefore, a new and low level inquiry based practical in gastrointestinal physiology was developed to provide context for the students while they responded to the questionnaire and survey arms of the study.

\section{Preparation and expected student outcomes}

Students were given an introductory tutorial on the use of the Powerlabdigital data acquisition system (ADInstruments, Bella Vista, New South Wales, Australia) and the operating LabChart software (Version LabChart Pro for Windows and Mac, ADInstruments). The tutorial included teaching about essential skills such as calibration of the force generated by contracting intestinal smooth muscle, measuring trough to peak force amplitude and contraction frequency on the LabChart recording, and adding selected numeric data to theLabChart data-pad. The robust and wellstudiedmodel, the guinea-pig ileum was utilised (Munro 1951). The dissection was performed by the lecturer with the students responsible for attaching the ileal loops to the equipment. An introductory 
talk was given before the experiment started during which the students were told they would be given four agonists (carbachol, histamine, noradrenaline and nicotine) that may or may not stimulate the force and frequency of ileal contraction. Their first learning outcome was to identify the receptors in the ileum based on the effects of the different agonists. They were also told they would be given four antagonists (atropine, hexamethonium, pyriline and phentolamine), however they were not told which antagonist paired with which agonist. Their second learning outcome therefore was to determine the different pairings and the third learning outcome was to work out in which order to add the agonist and antagonist. The remainder of the introductory talk concentrated on a revision of the equipment. A lecturer and a demonstrator were available throughout the experiment. A full laboratory report (consisting of introduction, aims, methods, results, discussion and references) was required.

\section{The experiment}

Students worked in groups of two-four (10 set ups per laboratory, a maximum number of 40 students in the laboratory at one time) and had a total of 3 hours to complete the 3 activities (identify the effects of the agonists and the receptors present, identify which agonist paired with which antagonist and identify the order in which to add the agonist and antagonist). The gastrointestinal experimental preparation involved the students suspending an approximately $2.5 \mathrm{~cm}$ loop of guinea-pig intestinal ileum on hooks, one of which was connected via a force transducer to the Powerlab. This enabled measurements of the force and rate of contraction. The suspended tissue was then lowered into a water-jacketed (to maintain the temperature at $37^{\circ} \mathrm{C}$ ) and oxygenated bath. The bath had markings on it to indicate volumes of 18,19 and $20 \mathrm{ml}$. For the investigations of which antagonist paired with which agonist the students were told to add $18 \mathrm{ml}$ of the maintenance solution to the bath followed by $1 \mathrm{ml}$ of their choice of agonist or antagonist and $1 \mathrm{ml}$ of the opposite compound. Thus if students added antagonist first they added agonist second and vice versa. Adding less than or more than $1 \mathrm{ml}$ of each of the compounds would give an incorrect concentration that could alter their results, so students were informed about the importance of being accurate with their volume measurements. Each group of students was given $10 \mathrm{ml}$ of each agonist and $10 \mathrm{ml}$ of each antagonist. Spare ileal loops were available.

Performed correctly the students should have started by testing the agonists on their own $(19 \mathrm{ml}$ maintenance solution plus $1 \mathrm{ml}$ agonist). This would have shown them that 3 of the agonists increased force of contraction, whilst noradrenaline had no effect (early segments of the ileum were used as it is known later segments are stimulated by adrenaline) (Munro, 1951). They should then have tested the agonists against the antagonists (antagonist added first) to see if the antagonist prevented the increase in the force of contraction for carbachol, nicotine and histamine. By a process of elimination they could then have deduced which antagonist went with adrenaline.

Students adopted various strategies for approaching this problem. For example some groups joined together and divided the antagonists between them. All groups had an internet enabled computer and some groups simply used Google to find out which antagonist paired with which agonist before testing each pair. As this still represented the students engaging in an investigative process they were not prevented from doing this. Other groups simply used a trial and error approach.

The questionnaire and survey

During the course of the laboratory practical 81 students out of a possible 113 completed a questionnaire and survey (response rate 71.7\%). The remaining students were either absent on the day of the experiment or chose not to participate. The questionnaire consisted of 12statementsdivided into 3 themes. The statements were:

1. It is apparent to me that practical work is a valuable part of this subject 
2. It is clear to me how the practical work in this subject will be assessed

3. I expect to be given detailed instructions on how to carry out each practical

4. I expect the practicals in this subject to be linked to the lecture material

5. I'd value the opportunity to design and carry out my own experiments

6. I am anxious about doing practicals in this subject

7. Well-designed practicals leave things for you to work out for yourself

8. I am looking forward to doing practicals in this subject

9. Explaining your results to others is an important part of practical work

10. A well designed practical gives clear cut results

11. If it were possible, I'd prefer not to do practicals in this subject

12. I expect to receive help during the practical when I need it

The themes were attitudes towards inquiry oriented learning; expectations about practicals in physiology; and attitudes towards the conduct of scientific experiments. The items were arranged in random order on the questionnaire. Subjects were asked to rate each statement using a 5-point Likert scale consisting of the categories: strongly agree, agree, neutral, disagree and strongly disagree. The percentage of students answering in each category was calculated. Students were also sub-divided according to Bachelor's degree (Animal Science, Biomedical Science, Exercise and Sports Science, Pharmacy, Science and Zoology). Their answers were scored where $1=$ strongly disagreed through to $5=$ strongly agreed. A comparison of the mean score for each question according to degree was made using the Kruskal Wallis non parametric ANOVA.

On the reverse side of the questionnaire were a numberof open ended questions. These included "please describe briefly any particular expectations and/or anxieties you have as you begin the laboratory component of this subject."

The questionnaire and survey were anonymous, and students were informed their participation was voluntary, and that their responses would not affect the marking of their practical report. They were asked to complete and return the questionnaire before leaving the laboratory.

\section{Results}

Theme 1 -attitudes towards inquiry-oriented learning in practicals

Figure 1 shows the percentage of students answering in each category for statements related to inquiry-oriented learning. Students were very positive about being given detailed instructions on how to carry out each experiment with $28.8 \%$ strongly agreeing and $53.8 \%$ agreeing. No-one either disagreed or strongly disagreed about this. There was also a firm belief that help should be provided when needed (63\% strongly agreed, 33.3\% agreed, no-one disagreed or strongly disagreed). Students were less decisive about whether they wanted to design and carry out their own experiments with $48.2 \%$ answering neutral, whilst $27.2 \%$ agreed and $12.4 \%$ strongly agreed. Only a total of $11.6 \%$ of students disagreed or strongly disagreed. In answer to the statement about well-designed practicals leaving things to be worked out $11.1 \%$ strongly agreed, $46.9 \%$ agreed, $33.3 \%$ were neutral and $8.6 \%$ disagreed.

Theme 2 - Expectations about practicals in physiology

All students either strongly agreed $(46.3 \%)$ or agreed $(53.8 \%)$ that practical work is a valuable part of physiology (Figure 2). A similarly high number expected the practicals to be linked to the lecture material (54.3\% strongly agreed, $40.7 \%$ agreed, no disagreement). Students were also fairly certain about the assessment with $25.9 \%$ strongly agreeing and $56.8 \%$ agreeing. Fifty one point nine percent of students looked forward to doing practicals in physiology with a further $13.6 \%$ strongly agreeing on this point, however $30.9 \%$ were neutral and $3.7 \%$ of students disagreed. Students were mostly 
positive about doing practicals in physiology. When asked about preferring not to do practicals in physiology, $17.3 \%$ strongly disagreed and $44.4 \%$ disagreed, although $25.9 \%$ were neutral, $8.6 \%$ agreed and $3.7 \%$ strongly agreed. Finally in this section, $44.4 \%$ of students were neutral about being anxious about doing physiology practicals, whilst 30.9\% disagreed, $8.6 \%$ strongly disagreed, $16.1 \%$ agreed and no-one strongly disagreed.

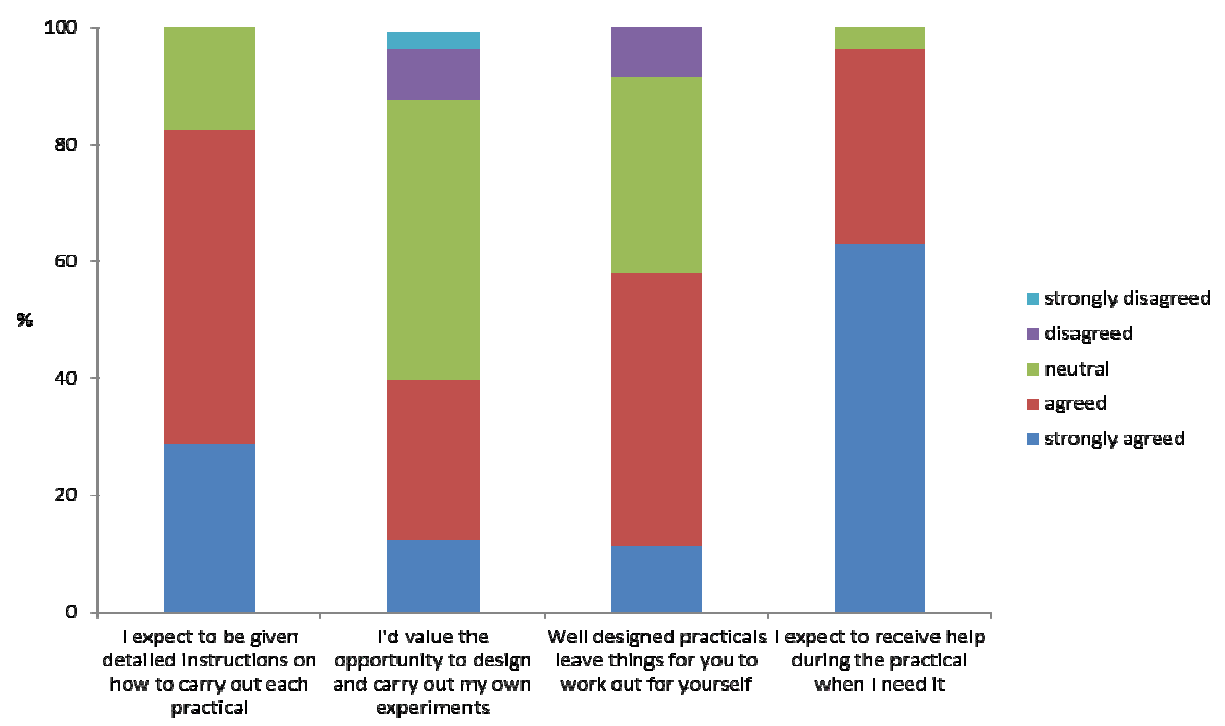

Figure 1.Student attitudes towards inquiry-based learning in practicals.Percentage of students answering strongly agreed (blue boxes); agreed (red boxes); neutral (green boxes); disagreed (purple boxes) or strongly disagreed (light blue boxes) to statements about inquiry based learning.

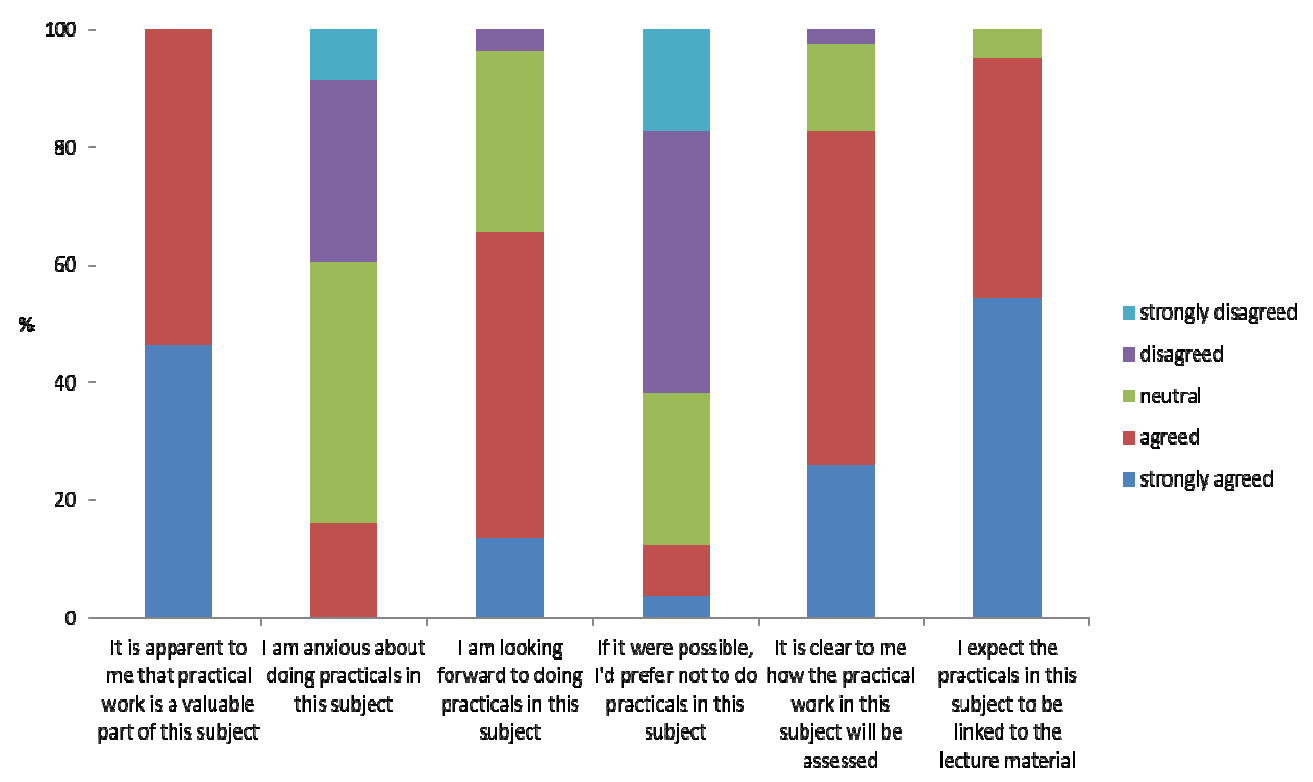

Figure 2.Student expectations about practicals in physiology.Percentage of students answering strongly agreed (blue boxes); agreed (red boxes); neutral (green boxes); disagreed (purple boxes) or strongly disagreed (light blue boxes) to statements about practicals in physiology.

\section{Theme 3 - General attitudes towards practicals}

The majority of the students believed that explaining your results to others is an important part of practical work, as $50.6 \%$ of students agreed, and $29.1 \%$ of students strongly agreed (Figure 3). Only $15.2 \%$ of students were neutral and $5.1 \%$ disagreed. Students were also largely sure that a well- 
designed practical gives clear cut results with $22.2 \%$ strongly agreeing and $44.4 \%$ agreeing on this matter. Twenty four point six nine percent of students were neutral and $8.6 \%$ disagreed; no-one strongly disagreed.

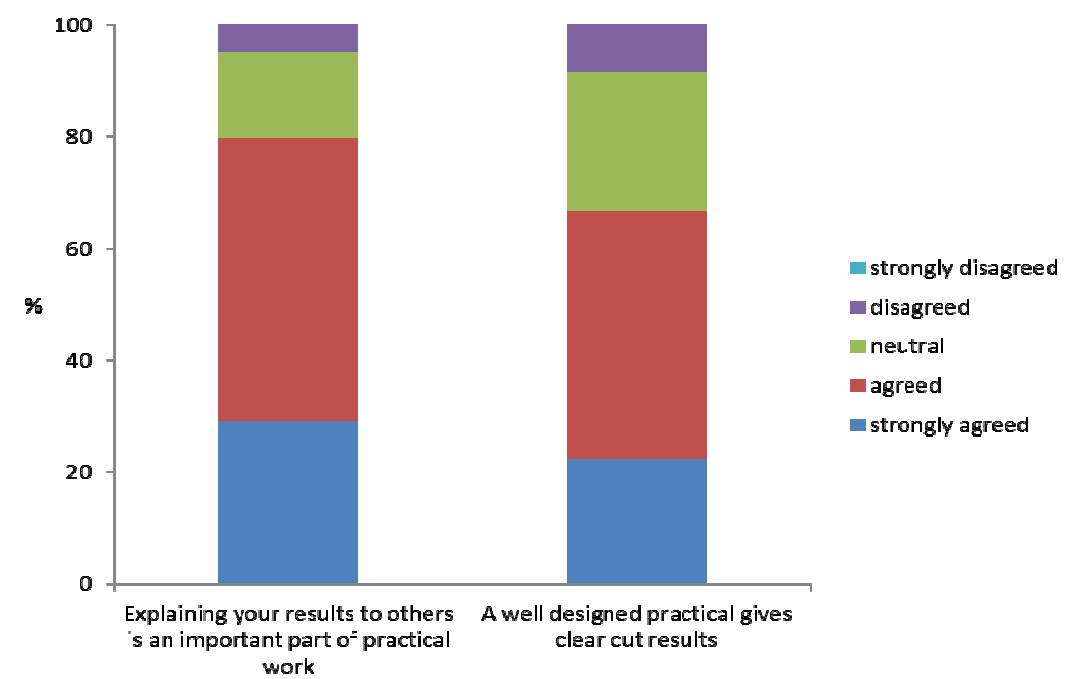

Figure 3: Student attitudes towards practicals. Percentage of students answering strongly agreed (blue boxes); agreed (red boxes); neutral (green boxes); disagreed (purple boxes) or strongly disagreed (light blue boxes) to statements about practicals.

When students were grouped according to Bachelor's degree (Animal Science, Biomedical Science, Exercise and Sports Science, Pharmacy, Science, Zoology) and their answers to the questionnaire scored, there were no significant differences in the mean scores for any of the questionnaire items (table 1).

Table 1: Comparison of the mean scores for each statement according to degree

\begin{tabular}{llllllll}
\hline Statement & $\begin{array}{l}\text { Animal } \\
\text { Science }\end{array}$ & $\begin{array}{l}\text { Biomedical } \\
\text { Sciences }\end{array}$ & BSc & Exercise & Pharmacy & Zoology & P value \\
\hline 1 & $4.4 \pm 0.1$ & $4.5 \pm 0.2$ & $4.6 \pm 0.1$ & $4.3 \pm 0.2$ & $4.6 \pm 0.2$ & $4.3 \pm 0.2$ & 0.521 \\
2 & $4 \pm 0.2$ & $4.1 \pm 0.2$ & $4.1 \pm 0.2$ & $4.1 \pm 0.1$ & $4 \pm 0.4$ & $3.9 \pm 0.2$ & 0.961 \\
3 & $4.3 \pm 0.2$ & $3.8 \pm 0.2$ & $4.3 \pm 0.2$ & $4.1 \pm 0.1$ & $3.9 \pm 0.2$ & $4.3 \pm 0.3$ & 0.200 \\
4 & $4.4 \pm 0.1$ & $4.4 \pm 0.2$ & $4.6 \pm 0.1$ & $4.6 \pm 0.2$ & $4.6 \pm 0.3$ & $4.9 \pm 0.1$ & 0.210 \\
5 & $3.1 \pm 0.3$ & $3.5 \pm 0.2$ & $3.1 \pm 0.2$ & $3.1 \pm 0.4$ & $4 \pm 0.4$ & $3.8 \pm 0.2$ & 0.100 \\
6 & $3.6 \pm 0.2$ & $2.9 \pm 0.3$ & $3 \pm 0.2$ & $3.7 \pm 0.2$ & $4 \pm 0.4$ & $3.1 \pm 0.4$ & 0.082 \\
7 & $3.8 \pm 0.2$ & $3.6 \pm 0.2$ & $3.5 \pm 0.2$ & $3 \pm 0.3$ & $3.9 \pm 0.4$ & $3.6 \pm 0.2$ & 0.254 \\
8 & $3.5 \pm 0.2$ & $3.6 \pm 0.2$ & $3.9 \pm 0.2$ & $3.4 \pm 0.4$ & $4.4 \pm 0.3$ & $3.9 \pm 0.2$ & 0.075 \\
9 & $4.0 \pm 0.2$ & $4.2 \pm 0.2$ & $4.0 \pm 0.2$ & $3.6 \pm 0.2$ & $4.7 \pm 0.2$ & $3.8 \pm 0.3$ & 0.077 \\
10 & $3.5 \pm 0.2$ & $3.8 \pm 0.4$ & $3.7 \pm 0.3$ & $4.1 \pm 0.1$ & $3.9 \pm 0.3$ & $3.8 \pm 0.2$ & 0.672 \\
11 & $2.6 \pm 0.2$ & $2.5 \pm 0.3$ & $2.2 \pm 0.3$ & $2.9 \pm 0.6$ & $1.9 \pm 0.6$ & $2.7 \pm 0.2$ & 0.345 \\
12 & $4.8 \pm 0.1$ & $4.5 \pm 0.2$ & $4.6 \pm 0.1$ & $4.7 \pm 0.2$ & $4.4 \pm 0.2$ & $4.6 \pm 0.1$ & 0.637 \\
\hline
\end{tabular}

Footnotes: data shown are means \pm S.E.

Answers to the survey

On the reverse side of the questionnaire were a number of open ended questions allowing the students to elaborate their answers. One of these questions was about student anxieties/expectations about inquiry based learning laboratories. Thirty nine students outlined their anxieties. There were a number of replies given by just a single student such as concerns over dissection or computer software or being made to think for yourself. The remainder of the answers fell into 7 categories as 
shown in table 2. The answer with the most responses was not understanding the practical: "just general confusion, but it gets better as the prac' goes on" and "I don't like feeling lost in the prac' and not knowing/understanding what we are supposed to be doing." Another popular response was obtaining the right results: "if the practical isn't conducted properly and the results are not the expected ones, since there is a practical write up which amounts to your final grade" and "anxious about data quality and reliability for experiments." This was followed by doing the practical before the theory has been covered and a lack of a clear explanation. The smallest number of responses concerned group work, the desire to leave the laboratory in good time and a lack of preparation on the students' part.

Table 2. Student responses to a statement asking them if they had any anxieties about performing practicals in physiology

\begin{tabular}{ll}
\hline Response & Number \\
\hline Not understanding the practical & 13 \\
Not getting the right results & 9 \\
Doing the practical before the theory is covered & 6 \\
Lack of clear explanation & 5 \\
Not getting out of the lab in a reasonable timeframe & 3 \\
Lack of preparation & 3 \\
Group work & 2 \\
\hline
\end{tabular}

Eighteen students responded that they had expectations of the practical element of this course. The commonest response (8 respondents) was that practicals would improve understanding of the course's content and that the practicals would be relevant to the lecture material: "I expect to get hands on experience with experiments that are relevant to the subject - the more interesting/fun the better." Two students expected to have clear explanations and 2 students expected to be challenged and stimulated: "I expected to be comfortably challenged and stimulated .... And I was." The other 6 responses included having a more interesting and hands on experience; learning how to handle the equipment; better prepared demonstrators; and, that the practicals would be more complex.

\section{Discussion}

The last twenty years have seen an increasing move towards the introduction of inquiry based practicals where students play a greater role in hypothesis generation and experimental design (Berg et al., 2003;Casottiet al., 2008; Chaplin, 2003;DiPasqualeet al., 2003;Henige, 2011;Kolkhorst et al., 2001;Nybo and May, 2015;Rivers, 2002). Unfortunately when this involves a sudden transition from the classical step-by-step instructions to full practical design this can leave the students feeling uncomfortable (Henige, 2011) and struggling (Kolkhorst et al., 2001). In this preliminary study we aimed to investigate student perceptions about inquiry based learning in physiology laboratories after a practical containing an element of inquiry. The element of inquiry involved students being partially involved in experimental design such that the students had to work out that they needed to test the agonists first and then what sequence to add antagonist and agonist in order to investigate which antagonist paired with which agonist.

Theme 1 - attitudes towards inquiry-oriented learning in practicals

Students clearly wanted detailed instructions (Figure 1). In addition only $40 \%$ of the students said they would value the opportunity to design and carry out their own experiments, whilst $48.2 \%$ of students were neutral on this point. This was the first time that these students had encountered inquiry based practicals in physiology. It could be that their uncertainty about whether they wanted more involvement in practical design reflected this inexperience. It has also been suggested that students find inquiry oriented learning hard work because of the lack of structure and guidance 
(Henige, 2011). Certainly the students expected to be given clear explanations (Figure 1) and were anxious when these were lacking (table 2). These data suggest that a sudden transition to full inquirybased learning without further scoping activities may not be suitable for these student cohorts.

\section{Further ideas for scoping activities}

One idea for how such a scoping activity could be introduced into a cardiovascular system physiology practical involves investigations in cardiac physiology using the electrocardiograph (ECG). The traditional approach to such a practical might involve providing the students with step by step instructions of how to measure increased heart rate during exercise; decreased heart rate during the diving reflex and both increased and decreased heart rate during the Valsalva manoeuvre (Levick, 2010). On the other hand in a scoping preliminary inquiry based practical students could be asked to design conditions producing these heart rate changes. Similarly students could be asked in a practical measuring peripheral blood flow to design conditions where an increase (exercise), a decrease (submersion of an extremity in ice cold water or the diving response) and an increase and decrease (Valsalva manoeuvre) (Levick, 2010) occurred. Given access to three different methods of making these measurements e.g. plethysmography, finger pulse transducer and Doppler, they could then be asked which of these methods they would choose to investigate suspected peripheral vascular disease in a patient.

\section{Theme 2 - Expectations about practicals in physiology}

Running university practicals is expensive both in terms of resources (chemicals, consumables etc) and staff time (Carnduff and Reid, 2003). As a result student practicals may be squeezed out of the curriculum. The data presented in Figure 2 suggests that students would clearly oppose this move. This is suggested by the student perception that practicals are a valuable part of physiology (Figure 2). Moreover students want to do practicals (contrast the looking forward vs. prefer not to do bars in figure 2). There is however an expectation that the practicals will be linked to the lecture material (Figure 2). Failure to realise this aim may account for some studies that show students do not get the point of what they are doing (Reid and Shah, 2007). It should be noted that this was referring to chemistry students but similar results have also been found in medical students in reference to biochemistry labs (Wills, 1974).

\section{Theme 3 - General attitudes towards practicals}

Students believed that explaining your results to others is an important part of practical work (Figure 3). This attitude is shared by Kirschner and Meester (1988) who also see the ability to clearly explain the experiment as important. Carnduff and Reid (2003) and Reid and Shah (2007) also rate the importance of reporting and presenting, which they put into categories of transferrable and general skills respectively. More specifically the ability to explain your results also speaks to the ability to handle data and understand the nature of the topic under investigation. This suggests that future laboratory assignments could contain an element of peer presentation either as a poster or a short talk.

One possible new insight is that a third of students were either neutral or disagreed that a welldesigned practical gives clear cut results (Figure 3). This suggests that further teaching is required on this matter.

\section{Anxieties and expectations}

There was a total of 41 responses to the statement about whether students had any anxieties about doing practicals (table 1), which was more than the 18 responses about expectations. An increased level of anxiety about inquiry based learning is also evident in the literature (Henige, 2011;SpronkenSmith et al., 2011). In our study, the greatest anxiety was that students would not understand the practical (table 2) and not get the right results. Although anxieties about not getting the right result may be typical of low level inquiry labs (Kolkhorst et al.,2001), it is equally likely that the reason 
students saw this as important was this practical required a full report (a full write up consisting of an introduction, aims, methods, results, discussion and references) which contributed to the students' final mark for this course. An unfortunate quirk of timetabling meant that practicals could not always be synced with the theoretical material. Understandably students were concerned when this happened and undoubtedly this added to their concerns about not understanding the practical (table 2 ), particularly since a better understanding of the lecture content was their greatest expectation. A challenge for future inquiry based activities will be getting the right balance between the level of detail in the instructions, providing clear explanations and maintaining/increasing the inquiry element.

The laboratory manual provided some background information on smooth muscle and smooth muscle contraction. On the grounds that not all the students would have read the laboratory manual the original iteration of this practical was initiated with a short 15-20 minute talk about smooth muscle contraction in the gastrointestinal tract. This talk was omitted from the new practical, and instead the introductory talk concentrated on the methods (i.e. how to use the equipment) for the practical. On reflection this may have been a mistake. Certainly a few introductory sentences about contraction being stimulated when effectors bind to their receptors and that the receptors could be identified through the use of agonists and antagonists could have provided the students with clearer instructions and alleviated some of their anxieties. In the future it may be best to re-introduce the initial short lecture as well as instructions on the methods.

Of interest, the majority of students in this study expressed concerns that may adversely impact on the ability to effectively implement inquiry based learning in the physiology laboratory context. Of particular concern in this regard, $82.5 \%$ of the students expected to receive extensive help and detailed instructions during the practical class activities, while only $39.5 \%$ of the students expressed a desire to design and carry out their own experiments. These findings suggest that considerable thought needs to be given as to how to best introduce physiology students to inquiry based practicals. Student concerns relating to a more independent inquiry based approach for physiology practicals may be due to a lack of self-confidence relating to the students' unfamiliarity with inquiry based practicals in physiology. It is therefore plausible that further experience with low level inquiry laboratories may be beneficial for this cohort of students before they embark on high level inquiry based learning in the physiology laboratory. This suggests that students should be gradually and increasingly introduced to inquiry based physiology practicals and that sudden exposure to full inquiry based practicals may result in significant student dissatisfaction and impaired learning outcomes.

\section{Conclusions}

In conclusion, to the best of our knowledge this is the first study to examine students' attitudes towards inquiry based learning in gastrointestinal physiology practical classes. The majority of students sawpracticals as an important part of physiology, did not wish for them to be removed and generally looked forward to doing them. However the majority of students expressed concerns that may impair the utility and effectiveness of implementing inquiry based learning in the physiology laboratory context, with $82.5 \%$ of the students expecting extensive help and detailed instructions during the practical class activities, and only $39.5 \%$ of the students expressing a desire to design and carry out their own experiments. These concerns may be due to a lack of self-confidence relating to the students' unfamiliarity with inquiry based practicals in physiology, and it is plausible thatfurther experience with low level inquiry laboratories may be beneficial for this cohort of students before they embark on high level inquiry based learning in the physiology laboratory. 


\section{Acknowledgements}

The authors express their gratitude to Professor Les Kirkup of the University of Technology, Sydney for the kind use of his questionnaire and survey questions.

\section{Grants}

This work was funded by a Teaching and Learning grant from the University of New England.

\section{References}

Berg, C.A.R., Bergendahl, V.C.B., Lundberg, B., and Tibell, L., (2003).Benefitting from an open-ended experiment?A comparison of attitudes to, and outcomes of, an expository versus an open-inquiry version of the same experiment.International Journal of Science Education,25, 351-372.

CARNDUFF, J., and REID, N.,(2003). Enhancing undergraduate chemistry laboratories, pre-laboratory and post-laboratory exercises, examples and advice, Education Department, Royal Society of Chemistry, Burlington House, Piccadilly, London.

Casotti, G., Rieser-Danner, L., and Knabb, M.T.,(2008).Successful implementation of inquiry-based physiology laboratories in undergraduate major and nonmajor courses.Advances in Physiology Education,32, 286-296.

Chaplin, S.B., (2003).Guided development of independent inquiry in an anatomy/physiology laboratory.Advances in Physiology Education, 27, 230-240.

Dipasquale, D.M., Mason, C.L., and Kolkhorst, F.W., (2003). Exercise in inquiry. Journal of College Science Teaching,32, 388-393.

Furtak, E.M., Seidel, T., Iverson, H., and Briggs, D. C.,(2012).Experimental and quasi-experimental studies of inquiry-based science teaching: a meta-analysis. Reviews in Educational Research82, 300-329.

Henige, K.(2011) Undergraduate student attitudes and perceptions toward low- and high-level inquiry exercise physiology teaching laboratory experiences. Advances in Physiology Education35, 197-205.

Kirschner, P.A., andMeester, M.A.M.,(1988).The laboratory in higher science education, problems, premises and objectives.Higher Education, 17: 81-98. 1988.

Kolkhorst, F.W., Mason, C.L.,Dipasquale, D.M., Patterson, P., andBuono, M.J.,(2001).An inquiry-based learning model for an exercise physiology laboratory course.Advances in Physiology Education, 25, 45-50.

Levick J.R., (2010).An introduction to cardiovascular physiology.5 $5^{\text {th }}$ Edition,CRC Press, Taylor \& Francis Group, Boca Raton, Florida, USA.

Munro, A.F.,(1951).The effect of adrenaline on the guinea-pig intestine.Journal of Physiology,112, 84-94.

Myers, M.J., and Burgess, A.B.,(2003).Inquiry-based laboratory course improves students' ability to design experiments and interpret data. Advances in Physiology Education,27, 26-33.

Nybo, L., and May, M.,(2015).Effectiveness of inquiry-based learning in an undergraduate exercise physiology course.Advances in Physiology Education,39, 76-80.

Reid, N., and Shah, I.,(2007).The role of laboratory work in university chemistry. Chemistry Education Research and Practice,8, 172-185.

Rivers, D.B.,(2002).Using a course-long theme for inquiry-based laboratories in a comparative physiology course.Advances in Physiology Education, 26, 317-326.

Spronken-Smith, R.,Walker, R., Batchelor, J.,O'Steen B., and Angelo, T.,(2011).Enablers and constraints to the use of inquirybased learning in undergraduate education.Teaching in Higher Education,16, 15-28.

Wills, E.D.,(1974).Comparison of student performances tested by continuous assessment and by a final examination,in Billing, D. E. Parsonage, J. R. (eds), Research into tertiary science education, Society for Research into Higher Education, London. 